\title{
Intercalation and Thermochemistry of Amines in Lamellar Titanium Phenylarsonate
}

\author{
V. S. O. Ruiz and C. Airoldi* \\ Instituto de Química, Universidade Estadual de Campinas, CP 6154, 13084-971 Campinas - SP, Brazil
}

\begin{abstract}
O composto lamelar fenilarsonato de titânio foi sintetizado e intercalado com alquilmonoaminas (metil a heptil), diaminoetano e diaminobutano, lutidina e $\alpha$-picolina. A matriz original foi caracterizada por análise elementar, difração de raios X, análise de superfície, porosidade, espectroscopia de absorção na região do infravermelho, termogravimetria e microscopia eletrônica de varredura. Os difratogramas de raios X não mostraram aumento significativo de distâncias interlamelares, e a intercalação foi comprovada por técnicas como a termogravimetria que indicou a perda de massa correspondendo às aminas. A condição ideal de intercalação foi efetuada com injeções de $30,0 \times 10^{-6}$ $\mathrm{dm}^{3}$ da amina $0,50 \mathrm{~mol} \mathrm{dm}^{-3}$ em suspensão de aproximadamente $10 \times 10^{-3} \mathrm{~g}$ das matrizes. Os números de moles intercalados com as alquilmonoaminas seguiram uma ordem aleatória em relação ao aumento da cadeia alifática, com valores entálpicos de -9,18 $\pm 0,07 ;-12,10 \pm 0,20 ;-7,61 \pm 0,02 ;-6,88 \pm 0,01$; $-9,47 \pm 0,03 ;-12,84 \pm 0,10$ e $-14,78 \pm 0,10 \mathrm{~kJ} \mathrm{~mol}^{-1}$ para a sequiência das alquilmonoaminas e variaram de $-3,66 \pm 0,30 \mathrm{a}-10,92 \pm 1,50 \mathrm{~kJ} \mathrm{~mol}^{-1}$ para alquildiaminas. Com as aminas aromáticas não ocorreu um efeito térmico significativo nas intercalações, fato que foi atribuído ao grande volume do grupo fenila presente no interior das lamelas, que impede a inserção da base na cavidade lamelar.
\end{abstract}

The lamellar compound titanium phenylarsonate was synthesized and intercalated with alkylmonoamines (methyl to heptyl), diaminoethane, diaminobutane, lutidine and $\alpha$-picoline. The host was characterized through elemental analysis, X-ray diffraction, surface analysis, porosity, infrared spectroscopy, thermogravimetry and electronic scanning microscopy. The intercalated compounds did not show significant increases in the interlamellar distances through X-ray diffractometry. The intercalation was confirmed by the thermogravimetric technique, indicating mass losses that correspond to the amines. The ideal intercalation was established by adding increments of $30.0 \times 10^{-6} \mathrm{dm}^{3}$ of $0.50 \mathrm{~mol} \mathrm{dm}{ }^{-3}$ of each amine into a suspension of about $10 \times 10^{-3} \mathrm{~g}$ of matrix. The number of moles intercalated with alkylmonoamines followed an aleatory order in relation to the increase of the aliphatic chain and the enthalpic values gave $-9.18 \pm 0.07 ;-12.10 \pm 0.20 ;-7.61 \pm 0.02$; $-6.88 \pm 0.01 ;-9.47 \pm 0.03 ;-12.84 \pm 0.10$ and $-14.78 \pm 0.10 \mathrm{~kJ} \mathrm{~mol}^{-1}$ for the sequence of alkylmonoamines and varied from $-3.66 \pm 0.30$ to $-10.92 \pm 1.50 \mathrm{~kJ} \mathrm{~mol}^{-1}$ for the alkyldiamines. The aromatic amines presented small thermal effects and the unfavorable intercalation is attributed to the large volume of the phenyl group inside the lamella, which hinders insertion of these bases inside the lamellar cavity.

Keywords: lamellar compound, intercalation, calorimetry, alkylmonoamines, alkyldiamines, aromatic amines

\section{Introduction}

A huge number of natural or synthesized materials, normally classified as typical inorganic substances, embodying clays, double hydroxides, phosphates, phosphonates, graphite, silicates, niobates, titanates and so on, ${ }^{1,2}$ are structurally fitted into well-formed, organized sheets, disposed as two-dimensional molecular crystals, having strong chemical interaction among these elements within the lamella, but with weak van der Waals forces to

\footnotetext{
*e-mail: airoldi@iqm.unicamp.br
}

bind the formed lamella together. The sequence presented by organized layers with a void cavity in between the sheets makes polar guest molecule insertion to occupy this free space easy, characterizing a typical acid-base interaction. However, the nature of the guest/host bonding interactions is in general not well-understood. ${ }^{3}$

The occurrence of an intercalation in a polar solvent causes some adjustment of the desired species in the available cavity. In any case, the great majority of lamellar compounds do not disturb the original inorganic structure 
or the van der Waals interactive forces and as the progress of intercalation takes place the sequence of lamella is normally maintained. ${ }^{4}$ Due to the versatility of inserting species inside the lamellar space, there is strong and increasing interest in producing new porous solids, to yield new materials with ions or molecules between the layers of these layered matrices. ${ }^{5}$ Known organic-inorganic hybrid materials containing open-framework structures ${ }^{6}$ are interesting not only as promising alternatives to carry out synthetic chemistry but also due to interest in the unusual features in their properties. ${ }^{7-12}$ These newly synthesized compounds combine useful organic and inorganic properties within the same lattice giving rise to sorption, ion-exchange, intercalation, catalysis, sensors and electronic, optical and magnetic properties. ${ }^{6,8,11-14}$ When these layers have attached phosphonate groups, the interlayer spaces of the lamella comprise organophosphate moieties with hydrophobic properties inside the lamellar space. ${ }^{15}$

From the precursor zirconium phenylphosphonate compound, with an interlayer spacing of $1470 \mathrm{pm},{ }^{16,17}$ considerable efforts have been applied to the chemistry of a series of new layered phosphonates, which was extended to phenylarsonates and phenylphosphinates with diverse structural variations, ${ }^{18-23}$ involving divalent, trivalent and tetravalent metals, ${ }^{6}$ with the purpose to explore some potential applications.

The tetravalent atoms belonging to phosphonate compounds are octahedrically coordinated through oxygen atoms originating from the attached moiety framework. ${ }^{16,24,25}$ Based on a possible material design principle, the ability to predict desired chemical and physical properties constitutes a central theme related to this synthetic research objective. ${ }^{10,26}$ The resulting layered materials, with well-defined structural and chemical internal void spaces, enables the presence of coordination sites, which are often useful to define structurally tailored materials. ${ }^{27,28}$

Most of the studies concerning phosphonate materials have been carried out with different organic pendant moieties, containing active functions like amino and carboxylic groups. The choice of metals, together with the organic groups attached to them, give a great variety of functionality to these compounds, which increases the potential applications. ${ }^{29}$

Research on phosphates and phenylphosphonates has previously investigated their synthesis, characterization, intercalation of amines, ion exchange and calorimetric studies, which provide a direct method for measuring the enthalpy of the acid-base interactions in the acid solid. ${ }^{30}$ Continuing this study, the intercalation behavior, energetic contributions and interactive effects at the solid/liquid interface of the reaction involving n-alkylmonoamines (methyl- to heptyl), n-alkyldiamines (diaminoethane, diaminobuthane) and cyclic amines (lutidine and $\alpha$-picoline) into titanium phenylarsonate, an analogue of phenylphosphonate, ${ }^{31,32}$ is now reported.

\section{Experimental}

\section{Chemicals}

All chemicals were at least analytical reagent grade. Phenylarsonic acid, $\mathrm{C}_{6} \mathrm{H}_{5} \mathrm{AsO}(\mathrm{OH})_{2}$ (Aldrich), and titanium chloride (Aldrich) having $10 \%$ of $\mathrm{TiCl}_{3}$ in $\mathrm{HCl}$ solution, were used as received. The aliphatic amines: methyl(Acros), ethyl- (Fluka), propyl- (Fluka), butyl (Riedel), pentyl- (Acros), hexyl- (Fluka) and heptyl- (Fluka) were distilled before use. For the methyl and ethylamines, originally in aqueous solutions, the distillate was passed through a sodium hydroxide column to retain humidity before bubling the vapor into dry ethanol. The alkyldiamines: diaminoethane (Riedel) and diaminobutane (Aldrich), lutidine (Really) and $\alpha$ - picoline (Aldrich) were used without prior purification. The amine solutions were standardized by titration using a $0.50 \mathrm{~mol}$ $\mathrm{dm}^{-3}$ hydrochloric acid solution, with a 5:1 mixture of bromine cresol green and methyl red as indicator.

\section{Synthesis}

Titanium phenylarsonate was synthesized by reacting phenylarsonic acid with acidic titanium trichloride. ${ }^{33}$

\section{Power versus time isotherms}

For the intercalation processes a sample of $10 \times 10^{-3} \mathrm{~g}$ of phenylarsonate sample was suspended in $2.0 \mathrm{~cm}^{3}$ of ethanol and calorimetrically titrated in a LKB 2277 Thermal Activity Monitor heat-flow instrument. After the sample was thermostated, increments of $10.0 \times 10^{-6} \mathrm{dm}^{3}$ of a titrand solution with a concentration of $0.50 \mathrm{~mol} \mathrm{dm}^{-3}$ were added successively to the suspension, through a Hamilton microsyringe with capacity of $0.25 \times 10^{-3} \mathrm{dm}^{3}$, at $298.15 \pm 0.20 \mathrm{~K}$. The complete titration consists in saturating the lamellar compound by the titrand. Three independent processes occur in the calorimetric solvent (S): a) thermal effects due to the host (PAP)/guest (G) interaction $\left.\left(\mathrm{Q}_{\mathrm{tit}}\right), \mathrm{b}\right)$ dilution of the guest solution $\left(\mathrm{Q}_{\mathrm{dil}}\right)$ and c) hydration of the host $\left(\mathrm{Q}_{\text {hid }}\right)$.

$\mathrm{PAP}_{(\mathrm{s})}+\mathrm{G}_{(\mathrm{s})}=\mathrm{PAP}_{(\mathrm{s})} \quad \mathrm{Q}_{\text {tit }}$ $\mathrm{G}_{(\mathrm{s})}+\mathrm{S}=\mathrm{G} \cdot \mathrm{S}_{(\mathrm{s})} \quad \mathrm{Q}_{\mathrm{dil}}$ 


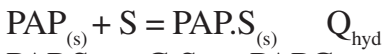

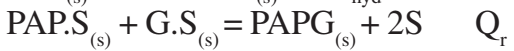

Based on the sequence of its calorimetric titration, the net thermal effect is given by $\Sigma Q_{\mathrm{r}}=\Sigma \mathrm{Q}_{\text {tit }}-\Sigma \mathrm{Q}_{\text {dil }}-\Sigma \mathrm{Q}_{\text {hyd }}$. As the thermal effect of hydration of the suspended inorganic lamellar host sample was null, then, $\Sigma \mathrm{Q}_{\mathrm{r}}=\Sigma \mathrm{Q}_{\mathrm{tit}}-\Sigma \mathrm{Q}_{\mathrm{dil}}$.

The integral enthalpy $\left(\mathrm{J} \mathrm{g}^{-1}\right)$ is calculated by the quotient between the resulting thermal effect integral (J) and the mass $(\mathrm{g})$ of the matrix used in the process: $\Delta \mathrm{H}=$ $\Sigma \mathrm{Q}_{\mathrm{r}} / \mathrm{m}$, whose enthalpic values were obtained after adjusting the experimental results to a modified Langmuir equation: ${ }^{34-37}$

$\frac{x}{\Delta_{R} h}=\frac{1}{(K-1) \Delta_{\text {int }} h}+\frac{x}{\Delta_{\text {int }} h}$

where $\mathrm{x}$ is the molar fraction of amine in the solution after each addition of the titrand, $\Delta_{\mathrm{R}} h$ is the integral enthalpy of reaction $\left(\mathrm{J} \mathrm{g}^{-1}\right), \mathrm{K}$ is a constant that includes the equilibrium constant and $\Delta_{\text {int }} h$ is the specific enthalpy of the interactive process. The value of $\mathrm{x}$ in this equation is obtained indirectly, due to the impossibility to determine the solute in the supernatant in the small volume inside the titration vessel, which also would break the equilibrium of each additional point. Thus, the isotherm of concentration was obtained by a batch method, maintaining similar conditions as used for the calorimetry. The data obtained are adjusted to another modified Langmuir equation: ${ }^{38}$

$\frac{C_{s}}{N_{f}}=\frac{C_{s}}{N_{s}}+\frac{1}{\left(N_{s} \cdot b\right)}$

where $\mathrm{C}_{\mathrm{s}}$ is the concentration of the guest $\left(\mathrm{mol} \mathrm{dm}^{-3}\right)$ that remained in solution after the intercalation, $\mathrm{N}_{\mathrm{f}}$ is the number of moles intercalated $\left(\mathrm{mol} \mathrm{g}^{-1}\right), \mathrm{N}_{\mathrm{s}}$ is the maximum amount of solute per gram of the host $\left(\mathrm{mol} \mathrm{g}^{-1}\right)$ and $\mathrm{b}$ is a constant. From the graphical representation of $\mathrm{C}_{\mathrm{s}} / \mathrm{N}_{\mathrm{f}}$ as function of $\mathrm{C}_{\mathrm{s}}$, a linearized form of the isotherm of concentration can be obtained, as shown in Figure 1. The angular and linear coefficients of the straight line enable calculation of $\mathrm{N}_{\mathrm{s}}$ and $\mathrm{b}$ constants from:

$b=\frac{1}{N_{s}} \quad$ and $\quad a=\frac{1}{K N_{s}}$

The molar enthalpy, $\Delta \mathrm{H}$, of the interaction process was calculated by considering the enthalpy of intercalation and the respective number of moles inserted, $\Delta \mathrm{H}=\Delta_{\mathrm{int}} \mathrm{H} / \mathrm{N}_{\mathrm{s}}$. Free Gibbs energy and entropy changes were calculated from $\Delta \mathrm{G}=-\mathrm{RT} \operatorname{lnK}$ and $\Delta \mathrm{G}=\Delta \mathrm{H}-\mathrm{T} \Delta \mathrm{S}$ expressions, respectively.

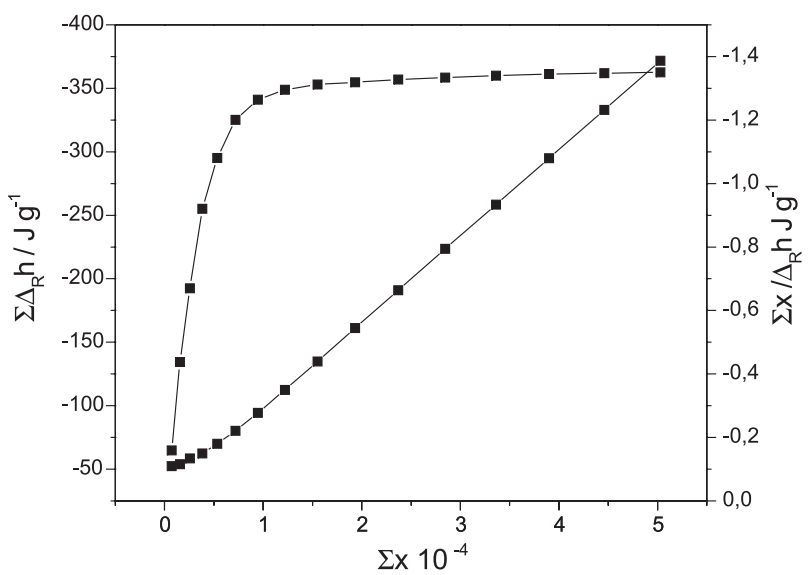

Figure 1. Isotherm for the integral enthalpy of intercalation $\Sigma \Delta_{R} \mathrm{~h}$ versus molar fraction SX, obtained from a calorimetric titration of $0.0100 \mathrm{~g}$ of titanium phenylarsonate suspended in $2.0 \mathrm{~cm}^{3}$ of ethanol with $0.4574 \mathrm{~mol} \mathrm{dm}^{-3}$ butylamine at $298.15 \pm 0.02 \mathrm{~K}$. The straight line is the linearized form of the isotherm.

\section{Isotherms of concentration}

These isotherms were obtained by maintaining the same host/guest calorimetric proportion. A series of ten samples of about $30 \times 10^{-3} \mathrm{~g}$ of host were suspended in $6.0 \mathrm{~cm}^{3}$ of ethanol. The guest molecules at $0.50 \mathrm{~mol} \mathrm{dm}^{-3}$, dissolved in the same solvent, were incrementally added to the suspension through a microsyringe. Each sample was stirred using a continuous orbital stirrer in a thermostated bath at $298 \pm 1 \mathrm{~K}$ and the equilibrium of the process was reached in approximately $15 \mathrm{~h}$. For each point of the isotherm, aliquots of $1.0 \mathrm{~cm}^{3}$ were removed from the supernatant and the amount of remaining amine was determined by titration with $0.0169 \mathrm{~mol} \mathrm{dm}^{-3}$ hydrochloric acid. Thus, these batch isotherms, having the same proportion as those used in the calorimeter, gave confidence that the reaction had occurred and compared by these two techniques.

The number of moles intercalated $\left(\mathrm{N}_{\mathrm{f}}\right)$ was calculated by means of the expression: $N_{f}=\left(n_{i}-n_{s}\right) / m$, where $n_{i}$ and $n_{s}$ are the initial and final number of moles, respectively, and $\mathrm{m}$ is the mass used, in grams.

\section{Characterization}

After digesting a sample of the original lamellar compound in a microwave instrument, the elements arsenic and titanium were determined in a Perkin-Elmer model Optima 3000 DV inductively coupled plasma optical emission spectrometer. ${ }^{39}$

Surface analysis and porosity were determined using a volumetric adsorption analyzer, ASAP 2010 from Micromeritrics, at $77 \mathrm{~K}$. The samples were pre-treated at $373 \mathrm{~K}$ for $24 \mathrm{~h}$ and submitted to $298 \mathrm{~K}$ in vacuum, reaching 
a residual pressure of $10^{-4} \mathrm{~Pa}$.

The X-ray diffraction patterns were obtained in a Shimadzu model XD3A diffractometer with $2 \theta$ in the 1.4 to $70^{\circ}$ range, with $\mathrm{CuK} \alpha 1.54060 \AA$ radiation.

The infrared spectra were performed on a Bomem FTIR, model $\mathrm{MB}$, spectrophotometer, using $\mathrm{KBr}$ pellets, collecting 50 scans in the 4000 and $400 \mathrm{~cm}^{-1}$ region with resolution of $4 \mathrm{~cm}^{-1}$.

The thermogravimetric curves were obtained on a TA instrument in an argon atmosphere, coupled with a model $1090 \mathrm{~B}$ thermobalance, with a heating rate of $0.167 \mathrm{~K} \mathrm{~s}^{-1}$, under a flow of $30 \mathrm{~cm}^{3} \mathrm{~s}^{-1}$ of synthetic air, varying from 300 to $1200 \mathrm{~K}$, with $10 \times 10^{-3} \mathrm{~g}$ of mass.

\section{Results and Discussion}

\section{Elemental analysis}

From the elemental analysis the molar ratio 2:1 for As:Ti was calculated. ${ }^{39}$ This correlation enables establishing the minimum formula of the synthetic compound as being $\mathrm{Ti}\left(\mathrm{O}_{3} \mathrm{AsC}_{6} \mathrm{H}_{5}\right)_{2}$.

\section{X-ray Diffraction}

The original lamellar host presented an interlayer distance ${ }^{6}$ of $1573 \mathrm{pm}$ at $2 \theta=5.66^{\circ}$. The ethanol was eliminated from the intercalated compounds at room temperature before diffractogram acquisitions. A proposed illustration for the distribution of the phenyl groups inside the interlayer space is represented in Figure 2. An increase to $1582 \mathrm{pm}$ at $2 \theta=$ $5.52^{\circ}$ occurred when the largest heptylamine molecule intercalates, to give a net increase of only $9 \mathrm{pm}$. This behavior differs from the normal process of intercalation, where the amine is inserted inside the interlayer region, to cause a significant increase in the interlayer distance. ${ }^{40}$ Based on the

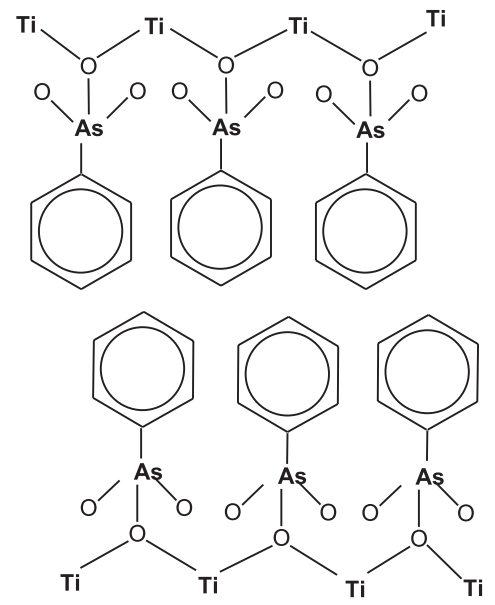

Figure 2. A schematic representation of the titanium phenylarsonate compound. results obtained, it is important to consider the length and volume of the phenyl group attached to the inorganic layer, whose value is, in principle, only superceded by amines larger than pentylamine, as reported before. ${ }^{16}$

\section{Infrared spectroscopy}

Selected spectra for the original host and when intercalated with heptylamine, diaminethane and diaminobutane are shown in Figure 3. All the spectra are very similar with a weak band at $3500 \mathrm{~cm}^{-1}$ due to residual humidity, which could accumulate in the anhydrous samples during sample preparation in $\mathrm{KBr}$ pellets and it can be eliminated by heating at $353 \mathrm{~K}^{6,25,41}$ When intercalated, the original broad band changing in shape with a slight maximum displacement to the $3676-3140 \mathrm{~cm}^{-1}$ interval, attributed to $\mathrm{N}-\mathrm{H}$ bond formation. ${ }^{13,16,25}$ Another vibrational mode appeared in the 2984 to $2824 \mathrm{~cm}^{-1}$ range that corresponds to amine $\mathrm{C}-\mathrm{H}$ bonds, ${ }^{25}$ showing changes in intensity and in the number of bands as the carbon amine chain increased. A small peak at $3047 \mathrm{~cm}^{-1}$ corresponds to the $\mathrm{C}-\mathrm{H}$ of the phenyl group, followed by a sharp and intense peak $\mathrm{k}^{6,25}$ at $1430 \mathrm{~cm}^{-1}$ and also peaks at 748 and $690 \mathrm{~cm}^{-1}$. As expected, all compounds presented bands in the 1147 to $1033 \mathrm{~cm}^{-1}$ region that correspond to the vibrations associated with the arsonate group.

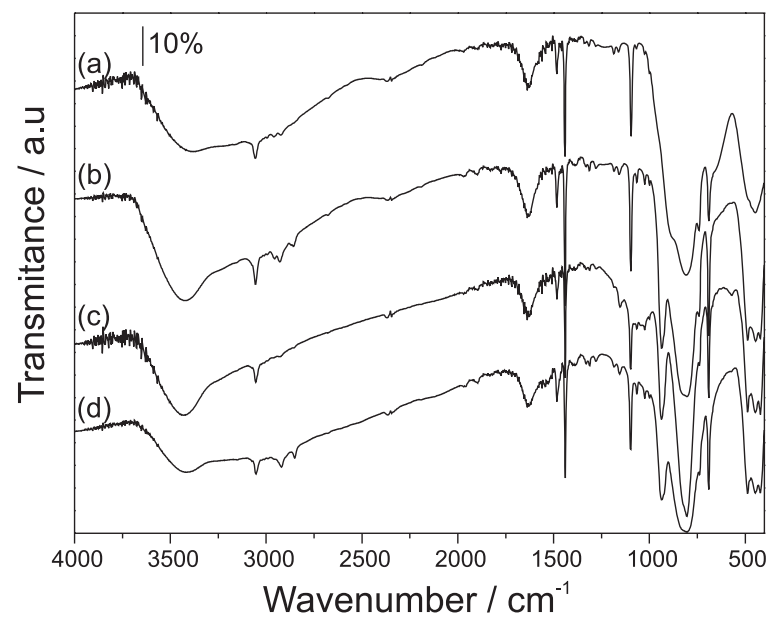

Figure 3. Infrared spectra of titanium phenylarsonate (a) and the intercalated compounds with heptylamine (b); diaminoethane, (c) diaminobutane $(\mathrm{d})$.

\section{Thermogravimetry}

The thermogravimetric curves of the original host intercalated with alkylmonoamines showed the elimination of amine, to give $5.0 \%$, which is followed by phenyl group decomposition, corresponding to $50.0 \%$ to give a product stable at $800 \mathrm{~K}$ and the increase in temperature ended in the final residue, ${ }^{6,16,35}$ as shown in Figure 4 (a). The 
intercalated compounds presented phenyl decomposition at lower temperatures in relation to the original host, Figure 4 (b-j). The calculated amount is also lower than the expected value for original and intercalated hosts. ${ }^{6.7}$ In the case of the intercalated compounds, some mass of amine should be eliminated. However, there is no correlation with the increase in the amine carbon chain length.

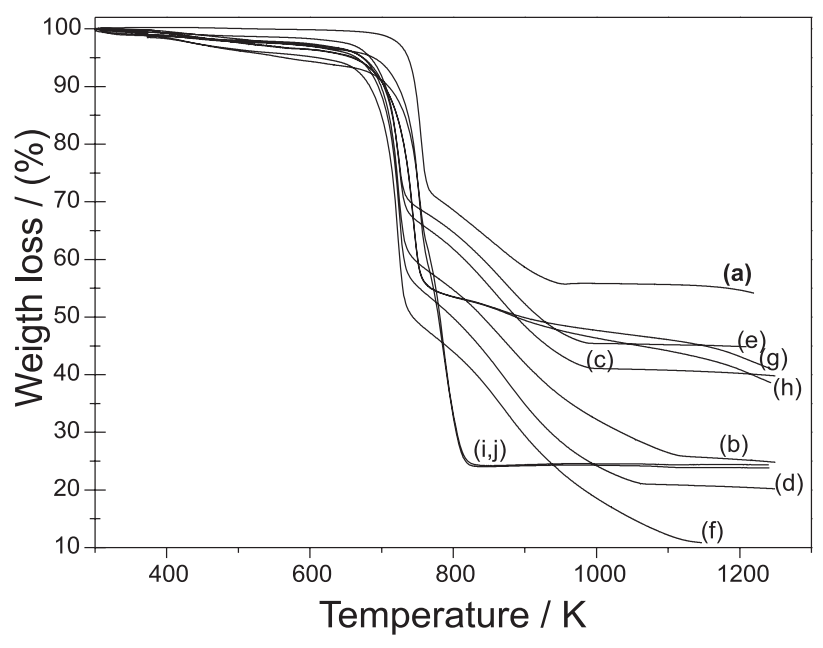

Figure 4. Thermogravimetric curves for titanium phenylarsonate (a) and the corresponding intercalated compounds with methyl(b), ethyl- (c), propyl- (d), butyl- (e), pentyl- (f), hexyl- (g), heptylamines (h), diaminoethane (i) and diaminobutane (j).

\section{Surface and porosity}

The lamellar host compound presented a surface area of $129.6 \pm 5.2 \mathrm{~m}^{2} \mathrm{~g}^{-1}$ and pore volume of $0.183 \mathrm{~cm}^{3} \mathrm{~g}^{-1}$, obtained from the BET procedure. This value was changed after intercalation of $0.50 \mathrm{~mol} \mathrm{dm} \mathrm{dm}^{-3}$ butylamine in ethanol, ${ }^{42,43}$ to give $113.3 \pm 4.4 \mathrm{~m}^{2} \mathrm{~g}^{-1}$ and pore volume of $0.026 \mathrm{~cm}^{3} \mathrm{~g}^{-1}$. This decrease in area can be interpreted as due to the difficulty of gaseous nitrogen to cover the space as the intercalation takes place. By considering the diameter of the pores, it is observed that the value is less in the intercalated material, indicating that the presence of amine reduced the volume of the pores, sufficient to cause blockage of nitrogen to all the pores.

Based on those results, high surface area gives advantages from the point of view of technological use. ${ }^{42}$ Isotherms of adsorption/desorption of gaseous nitrogen at $77 \mathrm{~K}$ of the original host and when intercalated with butylamine are shown in Figures 5 A and B, respectively. The isotherms present two inflections, the first one, between $\mathrm{P} / \mathrm{Po}=0$ to 0.05 , is due to formation of a monolayer of gaseous adsorbent and the second one, between $\mathrm{P} / \mathrm{Po}=$ 0.1 to 0.9 , shows the gas filling and condensing in the mesopores, followed by nitrogen condensation in the macropores. Mesopores have widths between 2 and 50 $\mathrm{nm}^{44}$ and can be characterized by nitrogen condensation, showing hysteresis in average and high pressures with the form of the isotherm conforming to a defined $\mathrm{H} 2$ type classification. $^{43}$
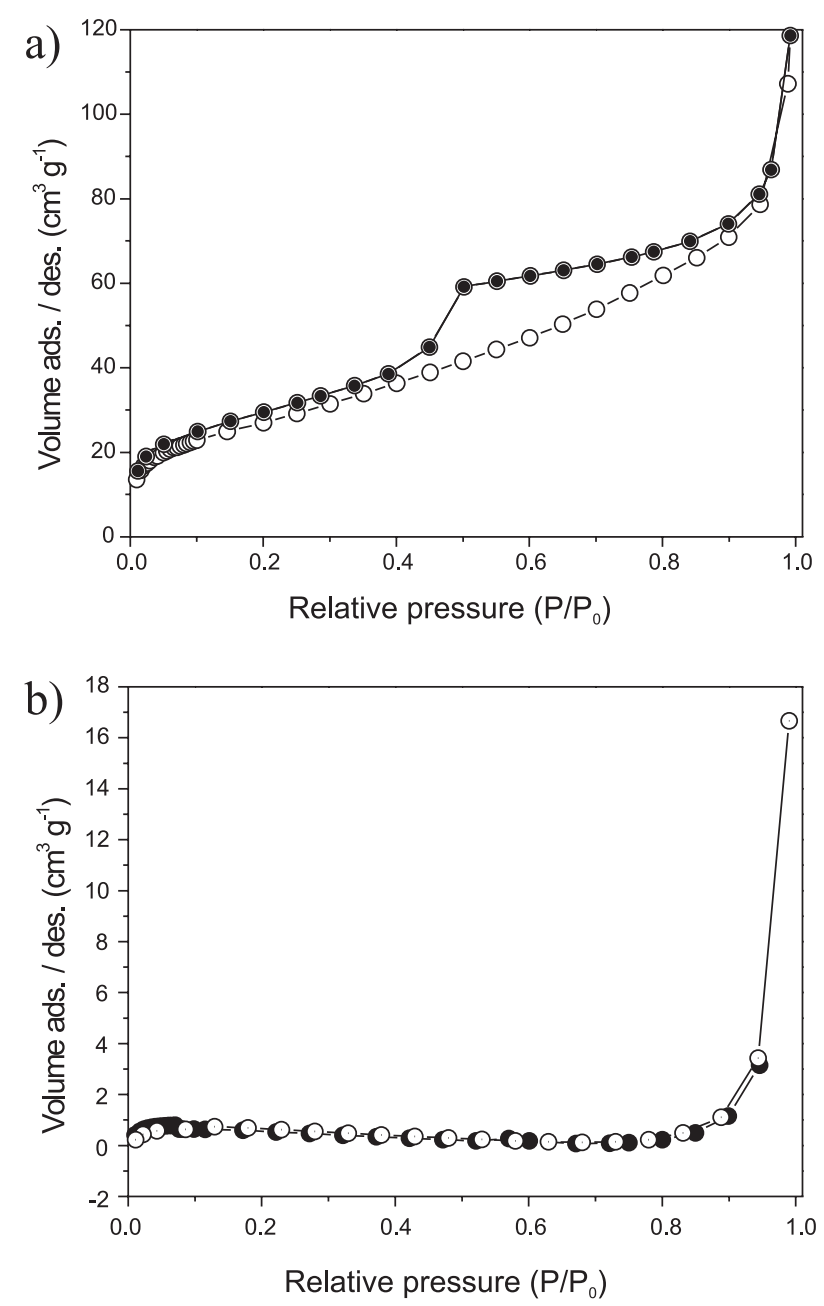

Figure 5. Nitrogen adsorption $(\mathrm{O})$ - desorption $(\bullet)$ in titanium phenylarsonate $(\mathrm{A})$ and intercalated with butylamine (B).

\section{Isotherms of time}

From these isotherms it could be verified that approximately $50 \mathrm{~h}$ is enough time for methylamine saturation and $10 \mathrm{~h}$ for the other monoamines. The isotherms involving diaminoethane and diaminobutane demonstrate that the saturation takes nearly $10 \mathrm{~h}$. All isotherms of concentration for alkylmonoamines and alkyldiamines were studied through calorimetry, which established the conditions to be applied to the batch processes. However, for the aromatic amines $\alpha$-picoline and lutidine, an insignificant thermal effect was observed. The small effects were closer to those obtained only from 
constant dilution effects. These small thermal effects could relate to the steric hindrance of the phenyl amine group and the values obtained did fit reasonably to an isotherm. However, for the alkylmonoamines and the alkyldiamines, reasonable results provided enough data to describe intercalation in such systems.

\section{Isotherms of concentration}

The isotherms obtained from the batch method for alkylmonoamines were collected through supernatant sample titrations and demonstrated the saturation of the host by reaching a maximum amount of intercalation of $1.88 \mathrm{mmol} \mathrm{g}^{-1}$ for butylamine, ${ }^{34}$ indicating a preference for this amine.

The sequence of intercalations did not follow mass or length of the amine chains, presenting a random order, which could be related to the normal difficulty in the entrance of the guest molecule into the lamella of the phenylarsonate. This fact seems to be associated with the presence of the phenyl group attached to the main phosphate group that can hinder the mobility of these amines as the intercalation is in progress. However, an increase in the number of moles intercalated $\left(\mathrm{N}_{\mathrm{f}}\right)$ with the concentration of the supernatant $\left(\mathrm{C}_{\mathrm{s}}\right)$ for each amine was clearly observed.

The intercalation of alkyldiamines showed a small preference for diaminoethane, with the value of 2.31 mmol g-1, which is higher in comparison with the most intercalated monoamine, as seen from butylamine with the value of $1.88 \mathrm{mmol} \mathrm{g}^{-1}$. From the structural point of view it is expected that larger alkyldiamines have little freedom to adjust inside the interlayer space, however, in the present case, also the largest diamine, diaminobutane, gave a value of $2.01 \mathrm{mmol} \mathrm{g}^{-1}$. Therefore, considering that the monoamines interact with the acidic centers on the lamellar compound, as should occur with this titanium phenylarsonate, whose value is $2.36 \mathrm{mmol} \mathrm{g}^{-1}$, the alkyldiamines reached almost the totality of the available sites. In this case, it must be considered that each amino group should be interacted with a free acidic site and for alkyldiamine two of them are required. Assuming that all sites are potentially used, in principle, two times more molecules of alkylmonoamine are needed for interacting with the total acidic host centers. Based on these results it seems that as a monoamine is intercalated, its volume hinders the entrance of the neighbor one and the total intercalation is reduced as observed in the listed value in Table 1.

\section{Calorimetry}

All thermochemical data obtained from the titration method involving the crystalline lamellar compound are shown in Table 1. As observed, the values of variation in enthalpy for all the amines are exothermic in nature, however, they do not follow a well-defined order, when considering the sequence of the aliphatic amine chains. ${ }^{45}$ In the same direction, the specific enthalpic values for the interactive processes $\left(\Delta_{\text {int }} \mathrm{h}\right)$ do not follow a linear order with the increase of the carbon atom chains, as was also observed for other systems..$^{34,35,37,45}$ It seems that the explanation for this behavior can be related to amine interferences in the free interlayer space of the lamella, which is already occupied by the voluminous phenyl group. The increase of the amine chains assumes a more complex arrangement that contributes to the lack of an order sequence of values. The low enthalpic values obtained for all amines give an indication that the interactive process occurred on the lamellar surface and presumes physical participation effects.

The Gibbs free energy values for this system are all negative, indicating that the reactions between host and amine are spontaneous in nature, but also do not follow a sequence, as already observed with the enthalpy variations, and are very close, with only small fluctuations. The positive entropic values, calculated from enthalpy and Gibbs free energy values, also contribute as an addition part to the system, as the interactive effect occurred for all

Table 1. Thermochemical data for amines intercalated into titanium phenylarsonate

\begin{tabular}{|c|c|c|c|c|c|c|c|c|}
\hline $\mathrm{R}-\mathrm{NH}_{2}$ & $-\Delta_{\text {int }} \mathrm{h} / \mathrm{J} \mathrm{g}^{-1}$ & $\mathrm{~N}_{\mathrm{f}} / \mathrm{mmol} \mathrm{g}^{-1}$ & $\mathrm{~N}_{\mathrm{s}} / \mathrm{mmol} \mathrm{g}^{-1}$ & $-\Delta \mathrm{H} / \mathrm{kJ} \mathrm{mol}^{-1}$ & $\mathrm{~K} \times 10^{4}$ & $\ln \mathrm{K}$ & $-\Delta \mathrm{G} / \mathrm{kJ} \mathrm{mol}^{-1}$ & $\Delta \mathrm{S} / \mathrm{J} \mathrm{K}^{-1} \mathrm{~mol}^{-1}$ \\
\hline $\mathrm{CH}_{3}-$ & 14.78 & $1.61 \pm 0.01$ & $1.61 \pm 0.01$ & $9.18 \pm 0.07$ & 5.66 & 10.94 & $27.1 \pm 0.2$ & $60 \pm 1$ \\
\hline $\mathrm{CH}_{3}-\mathrm{CH}_{2}-$ & 21.29 & $1.76 \pm 0.01$ & $1.76 \pm 0.01$ & $12.10 \pm 0.20$ & 1.53 & 9.63 & $23.9 \pm 0.4$ & $40 \pm 1$ \\
\hline $\mathrm{CH}_{3}^{3}-\left(\mathrm{CH}_{2}^{2}\right)_{2}-$ & 14.08 & $1.85 \pm 0.01$ & $1.85 \pm 0.01$ & $7.61 \pm 0.02$ & 7.40 & 11.21 & $27.8 \pm 0.1$ & $68 \pm 1$ \\
\hline $\mathrm{CH}_{3}-\left(\mathrm{CH}_{2}\right)_{3}^{-}$ & 12.93 & $1.88 \pm 0.01$ & $1.88 \pm 0.01$ & $6.88 \pm 0.01$ & 8.48 & 11.35 & $28.1 \pm 0.1$ & $71 \pm 1$ \\
\hline $\mathrm{CH}_{3}^{3}-\left(\mathrm{CH}_{2}\right)_{4}^{-}$ & 14.40 & $1.52 \pm 0.01$ & $1.52 \pm 0.01$ & $9.47 \pm 0.03$ & 1.89 & 9.85 & $24.4 \pm 0.3$ & $50 \pm 1$ \\
\hline $\mathrm{CH}_{3}-\left(\mathrm{CH}_{2}\right)_{5}^{-}$ & 17.47 & $1.36 \pm 0.01$ & $1.36 \pm 0.01$ & $12.84 \pm 0.10$ & 39.00 & 12.87 & $31.9 \pm 0.1$ & $63 \pm 1$ \\
\hline $\mathrm{CH}_{3}^{3}-\left(\mathrm{CH}_{2}\right)_{6}^{-}$ & 19.81 & $1.34 \pm 0.01$ & $1.34 \pm 0.01$ & $14.78 \pm 0.10$ & 13.30 & 11.80 & $29.3 \pm 0.1$ & $48 \pm 1$ \\
\hline $\mathrm{H}_{2} \mathrm{~N}\left(\mathrm{CH}_{2}\right)_{2}^{-}$ & 8.47 & $2.30 \pm 0.01$ & $2.31 \pm 0.01$ & $3.66 \pm 0.30$ & 2.77 & 10.23 & $25.3 \pm 0.2$ & $72 \pm 1$ \\
\hline $\mathrm{H}_{2} \mathrm{~N}\left(\mathrm{CH}_{2}\right)_{4}^{-}$ & 21.96 & $1.65 \pm 0.01$ & $2.01 \pm 0.01$ & $10.92 \pm 1.50$ & 20.80 & 12.24 & $18.9 \pm 0.1$ & $27 \pm 1$ \\
\hline
\end{tabular}


cases. These positive values can be related to the substitution of the original solvent molecules bonded to the inorganic matrix as well as for those molecules associated with the amine molecules, which are freed to the medium after intercalation, causing an increase in entropy of the system. ${ }^{46}$ These thermodynamic data reflect the favorable set of values, when the basic nitrogen atoms interact with the acidic centers available inside the lamellar structure of this inorganic matrix.

\section{Conclusions}

The crystalline lamellar titanium phenylarsonate compound synthesized had its stoichiometry established through elemental analyses using the ICP OES technique. The alkylmonoamines, alkyldiamines and aromatic amines were intercalated better using ethanol as solvent, rather than water, as demonstrated by calorimetry, and by batch methods. The presence of the intercalated amines was clearly observed from interlayer expansion, the decrease in surface area and thermogravimetric curves. The unsuccessful cyclic amine intercalation could be due to steric hindrance from the attached phenyl groups of the original inorganic matrix inside the interlayer cavity. The maximum alkylmono and dialkylamine intercalations needed to saturate the matrix were 1.88 and $2.13 \mathrm{mmol} \mathrm{g}^{-1}$ for butylamine and diaminoethane, respectively. However, these values are lower than the maximum capacity of 2.36 mmol g-1 proposed for the original matrix, calculated through elemental analysis. The equilibrium at the solid/ liquid interface gave favorable thermodynamic data expressed by exothermic enthalpy, negative Gibbs free energy and positive entropy.

\section{Acknowledgements}

The authors are indebted to FAPESP for a fellowship to V.S.O. R. and financial support and CNPq for a fellowship to C.A.

\section{References}

1. Wang, W.; Tang, Y.; Kapplen, M.; He, N.; Weiming, H.; Gao, Z.; Microp. Mesop. Mater. 2001, 42, 219.

2. Alberti, G.; Dionigi, C.; Giontella, E.; Mascarós, S.M.; Vivani, R.; J. Colloid Interface Sci. 1997, 188, 27.

3. Dines, M.B.; J. Chem. Educ. 1974, 51, 221.

4. Lima, C.B.A.; Airoldi, C.; Solid. State Sci. 2003, 4, 1321.

5. Alonzo, G.; Bertazzi, F.N.; Ginestra, C.; Massucci, M.A.; Patrono, P.; J. Mater. Chem. 1997, 7, 135.
6. Morizzi, J.; Hobday, M.; Rix, C.; J. Mater. Chem. 2000, 10, 1693.

7. Raki, L.; Detellier, C.; Chem. Commum. 1996, 2475.

8. Lei, C.; Mao, J.; Sun, Y.; J. Solid. State Chem. 2004, 177, 2449.

9. Alcántara, M.M.G.; Cabeza, A.; Aranda, M.AG.; Guagliardi, A.; Mao, J.G.; Clearfield, A.; J. Solid. State Sci. 2004, 6, 479.

10. Ngo, H.L.; Hu, A.; Lin, W.; J. Mol. Catal. Chem. 2004, 215 , 177.

11. Ali, F.A.; Déjugnat, C.; Moghadam, G.E.; Lattes, I.R.; J. Colloid Interface Sci. 2004, 273, 512.

12. Stock, N.; Stoll, A.; Bein, T.; Microp. Mesop. Mater. 2004, 69, 65.

13. Fredoueil, F.; Massiot, D.; Janvier, P.; Gingl, F.; Doeuff, E.M.B.; Clearfield, A.; Bujoli, B.; Inorg. Chem. 1999, 38, 1831.

14. Bellittoa, C.; Bauera, E.M.; Righinia, G.; Altomareb, A.; J. Magnet. Magnet. Mater. 2004, 272-276, 1060.

15. Hix, G.B.; Carter, V.J.; Wragg, D.S.; Morris, R.E.; Wright, P.A.; J. Mater. Chem. 1999, 9, 179.

16. Poojary, D.M.; Clearfield, A.; J. Am. Chem. Soc. 1995, 117, 11278.

17. Martin, K.J.; Squattrito, P.J.; Clearfield, A.; Inorg. Chim. Acta 1989, $155,7$.

18 Loiseau, T.; Neeraj, S.; Cheetham, A.K.; Acta Crystalogr. 2002, $58,379$.

19. Huang, Y.M; Whang, C.W.; Electrophoresis 1998, 19, 2140.

20. Liebl, B.; Muckter, H.; Nguyen, P.T.; Doklea, E.; Islambouli, S.; Fichtl, B.; Forth, W.; Appl. Organometal. Chem. 1995, 9, 531.

21. Wong, Y.W.; Kussie, P.H.; Parhamiseren, B.; Margolies, M.N.; J. Phenom. Immunol. 1995, 154, 3351.

22. Howard, A.G.; Hunt, L.E.; Anal. Chem. 1993, 65, 2995.

23. Cunningham, D.; Firtear, P.; Molloy, K.C.; Zuckerman, J.J.; J. Chem. Soc., Dalton Trans 1983, 1523.

24. Cunningham, D.; Hennelly, P.J.D.; Inorg. Chim. Acta 1979, 37, 95.

25. Zhang, Y.; Scott, K.J.; Clearfield, A.; J. Mater. Chem. 1995, 5, 315.

26. Sun, Z.M.; Mao, J.G.; Yang, B.P.; Ying, S.M.; J. Solid. State Sci. 2004, 6, 295.

27. Cao, G.; Mallouk, T.E.; Inorg. Chem. 1991, 30, 1434

28. Bruce, D.W.; O'Hare, D.; Inorganic Materials, $2^{\text {nd }}$ ed., John Wiley: London, 1988.

29. Menaa, B.; Shannon, I.J.; J. Mater. Chem. 2002, 12, 350.

30. Espina, A.; García, J.R.; Guil, J.M.; Jaimez, E.; Parra, J.B.; Rodríguez, J.; J. Phys. Chem. 1998, 102, 1713.

31. Ruiz, V.S.O.; Airoldi, C.; J. Therm. Anal. Calorim. 2003, 71, 459.

32. Ruiz, V.S.O.; Airoldi, C.; Thermochim. Acta 2004, 420, 73.

33. Ruiz, V.S.O.; Dias, S.L.P.; Gushikem, Y.; Bruns, R.E.; Airoldi, C.; J. Solid State Chem. 2004, 177, 675. 
34. Lima, C.B.A.; Airoldi, C.; Thermochim. Acta 2003, 400, 51.

35. Nunes, L.M.; Airoldi, C.; J. Solid. State Chem. 2000, 154, 557.

36. Jaroniec, M.; Madey, R.; Physical Adsorption on Heterogeneous Solids, Elsevier: New York, 1988.

37. Fonseca, M.G.; Airoldi, C.; Thermochim. Acta 2000, 359, 1.

38. Airoldi, C.; Alcântara, E.F.C.; J. Chem. Thermodynamics 1995, $27,623$.

39. Ruiz, V.S.O.; Airoldi, C.; Cur. Anal. Chem., 2005, 1, 171.

40. Airoldi, C.; Roca, S.; J. Mater. Chem. 1996, 6, 1963.

41. Haky, J.E.; Brady, B.; Dando, N.; Weaver, D.; Mater. Res. Bull. 1997, 32, 297.
42. Israëli, Y.; Besse, C.; Morel, J.; Desrosiers, J.N.; J. Chem. Soc., Dalton Trans. 2000, 791.

43. Anillo, A.A.; García, M.A.V.; Suárez, R.; Rodríguez, M.; J. Mater. Res. Bull. 1999, 34, 627.

44. Everett, D.H.; Pure Appl. Chem. 1972, 31, 579.

45. Lima, C.B.A.; Airoldi, C.; Int. J. Inorg. Mater. 2001, 3, 907.

46. Kosmulski, M.; Colloid. Surf. 1994, 83, 273.

Received: October 20, 2004

Published on the web: August 16, 2005

FAPESP helped in meeting the publication costs of this article. 